\title{
Characterizing Intrinsic Deactivation in Cobalt-Catalyzed Fischer-Tropsch Synthesis
}

\author{
C.E. Kliewer, G. Kiss, S.L. \\ Soled ExxonMobil Research and Engineering Co., Annandale, NJ, 08801
}

Three intrinsic deactivation modes observed in experimental cobalt Fischer-Tropsch synthesis (Co FTS) catalysts are investigated via ex-situ TEM [1]. These include: cobalt oxidation reversible by mild hydrogen treatment, cobalt agglomeration, and cobalt-support mixed oxide formation. All three mechanisms involve redox transformation of the catalytically active cobalt metal. Earlier studies have shown [2] that (a) $\mathrm{Co}^{0}$ is the catalytically active entity in Co FTS and (b) the site activity is not influenced by the support or the metal particle size in catalysts containing metal particles larger than $\sim 5 \mathrm{~nm}$. Steadystate isotope transient studies with similar catalysts [3] confirmed these conclusions. Consequently, transformations that reduce $\mathrm{Co}^{0}$ surface by agglomeration or by oxidizing Co particles will reduce catalytic activity.

Based on bulk thermodynamic data [4,5], CoO would not form under typical Co FTS conditions. However, reactor studies and TEM observations discussed here prove that the behavior of nanoscale metal particles deviates from that of the bulk and that cobalt oxidation does occur during commercially relevant Co FTS conditions. The exact nature of the oxidized species is not clear, but it is shown that the process is enhanced by higher $\mathrm{CO}$ conversion (higher $\mathrm{H}_{2} \mathrm{O} / \mathrm{H}_{2}$ ratio) and smaller particle size. This oxidation is fully reversed by hydrogen reduction at Co FTS temperature and pressure. Once the cobalt metal is oxidized, it wets the support surface. This process in turn may bring oxidized cobalt islands in contact. Subsequent reduction of contacting islands tends to form a single metal particle. Since this growth mechanism starts with metal oxidation, it is also enhanced by CO conversion and smaller particle size. However, due to the spatial proximity requirement, metal particle distances on the support surface also play a role.

References:

1. C.E. Kliewer, G. Kiss, G.J. DeMartin, Microscopy and Microanalysis 12 (2006) 135.

2. E. Iglesia, Appl. Catal. A: General 161 (1997) 59.

3. C.J. Bertole, C.A. Mims, G. Kiss, J. Catal. 221 (2004) 191.

4. E.T Turkdogan, Physical Chemistry of High Temp. Technology, Academic Press, NY, 1980.

5. O. Kubaschewski, C.B. Alcock, Metallurgical Thermochemistry, Fifth Ed., Pergamon, NY, 1979.

6. G. Kiss, C.E. Kliewer, G.J. DeMartin, C.C. Culross, J.E. Baumgartner, J. Catal. 217 (2003) 127 


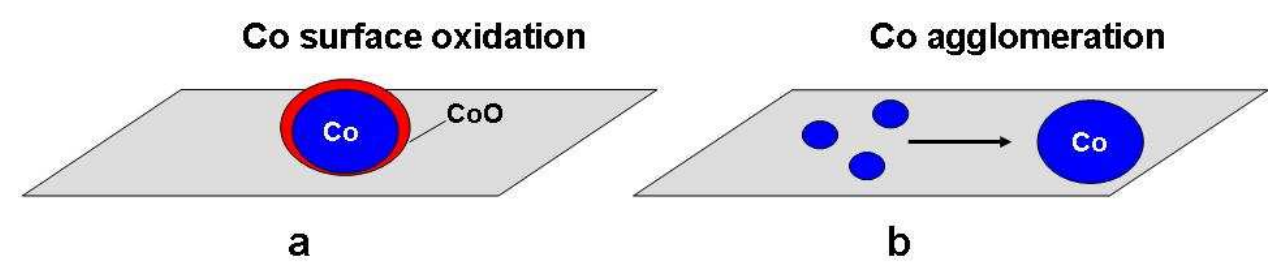

Co-support mixed oxide formation

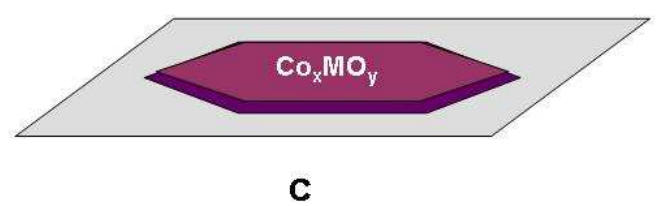

Figure 1: Schematic representing three intrinsic deactivation mechanisms in experimental supported Co-based FischerTropsch catalysts: metal oxidation, metal agglomeration, and mixed metal oxide formation. 